Article

\title{
Novel 5'-Norcarbocyclic Derivatives of Bicyclic Pyrrolo- and Furano[2,3-d]Pyrimidine Nucleosides
}

\author{
Anna A. Klimenko ${ }^{1}$, Elena S. Matyugina ${ }^{1}$, Evgeniya B. Logashenko ${ }^{2}$, Pavel N. Solyev ${ }^{1} \mathbb{D}$, \\ Marina A. Zenkova ${ }^{2}$, Sergey N. Kochetkov ${ }^{1}$ and Anastasia L. Khandazhinskaya ${ }^{1, *}$ \\ 1 Engelhardt Institute of Molecular Biology, Russian Academy of Sciences, 32 Vavilov St., Moscow 119991, \\ Russia; kanna76v@gmail.com (A.A.K.); matyugina@gmail.com (E.S.M.); solyev@gmail.com (P.N.S.); \\ kochet@eimb.ru (S.N.K.) \\ 2 Institute of Chemical Biology and Fundamental Medicine, Siberian Branch of Russian Academy of Sciences, \\ 8 Lavrentiev Ave., Novosibirsk 630090, Russia; evg_log@ngs.ru (E.B.L.); marzen@niboch.nsc.ru (M.A.Z.) \\ * Correspondence: khandazhinskaya@bk.ru; Tel.: +7-499-135-60-65
}

Received: 3 September 2018; Accepted: 12 October 2018; Published: 16 October 2018

check for updates

\begin{abstract}
Here we report the synthesis and biological activity of new $5^{\prime}$-norcarbocyclic derivatives of bicyclic pyrrolo- and furano[2,3-d]pyrimidines with different substituents in the heterocyclic ring. Lead compound 3i, containing 6-pentylphenyl substituent, displays inhibitory activity with respect to a number of tumor cells with a moderate selectivity index value. Compound $3 \mathbf{i}$ induces cell death by the apoptosis pathway with the dissipation of mitochondrial potential.
\end{abstract}

Keywords: 5'-norcarbocyclic nucleoside analogues; antiproliferative properties; structure-activity relationship

\section{Introduction}

Nucleic acid components are involved in many vitally important metabolic processes (DNA and RNA synthesis, cell signaling, enzyme regulation and metabolism); this is why their synthetic analogues are convenient tools for studying and influencing these processes. Nucleoside and nucleotide analogues can interact with and inhibit essential enzymes such as human and viral polymerases (DNA-dependent DNA polymerases, RNA-dependent DNA polymerases or RNA-dependent RNA polymerases), kinases, ribonucleotide reductase, DNA methyltransferases, purine and pyrimidine nucleoside phosphorylase and thymidylate synthase [1]. As a result, nucleoside analogues have been in clinical use for almost 50 years and have become cornerstones of treatment for patients with cancer or viral infections [1]. However, the clinical use of these compounds is limited by important side-effects and primary or acquired drug resistance [2]. Thus, the development of new antiviral and anticancer agents is of crucial importance.

Bicyclic furano[2,3-d]pyrimidine nucleosides were first developed by McGuigan et al. as herpes virus family inhibitors [3]. The compounds bearing the $2^{\prime}$-deoxyribose residue are non-toxic and are highly effective inhibitors of the Varicella-Zoster virus [4], and analogues containing the $2^{\prime}, 3^{\prime}$ dideoxyribose or acyclic fragments suppress human cytomegalovirus [5]. The corresponding carbocyclic analogue was also synthesized by the same group but turned out to be less active [6]. It was shown that in order to display antiviral activity bicyclic furano[2,3-d]pyrimidine nucleosides have to be phosphorylated by viral deoxythymidine kinase, but the complete mechanism of their inhibitory effect has not yet been elucidated [5]. At the same time, significant anticancer activity was found for several small molecules which include a furo[2,3-d]pyrimidine scaffold due to their inhibitory effect against different protein kinases $[7,8]$. Recent data have shown that some pyrroloand furano[2,3-d]pyrimidine nucleosides are able not only to suppress the growth of various lines 
of tumor cells, but also to induce apoptosis [9-11]. The first $5^{\prime}$-norcarbocyclic derivatives of bicyclic furano[2,3-d]pyrimidines with various alkyl substituents at the 6-position of the heterocyclic base have shown antitumor activity against different cell lines [12]. Here we synthesized new representatives of bicyclic furano[2,3-d]pyrimidine nucleosides and novel bicyclic pyrrolo[2,3-d]pyrimidine nucleosides to obtain structure-activity relationship data for this family of compounds and to get additional information on the mechanisms of action and potential cellular targets for these bicyclic nucleosides.

\section{Results and Discussion}

\subsection{Chemistry}

All the $5^{\prime}$-norcarbocyclic analogs of bicyclic furano- and pyrrolo[2,3d]pyrimidine nucleosides were synthesized starting from the general precursor racemic $1-\left(4^{\prime}\right.$-hydroxy-2'-cyclopentene- $\left.1^{\prime}-\mathrm{yl}\right)-5-$ ioduracil 1 (Figure 1) which was obtained as described earlier [12,13]. 1-(2', $3^{\prime}, 4^{\prime}$-Trihydroxycyclopent$1^{\prime}$-yl)-5-iodouracil 2 was synthesized by oxidation of compound 1 using osmium tetroxide in the presence of $N$-methylmorpholine- $N$-oxide (NMMO) [14]. This procedure allows the $c i s-2^{\prime}, 3^{\prime}$-diol to be obtained selectively $[15,16]$. To prepare furano[2,3d]pyrimidine nucleosides we used $\mathrm{Cu} / \mathrm{Pd}$-catalyzed cyclisation of $\mathbf{1}$ (for $\mathbf{3 a} \mathbf{a}-\mathbf{i}$ ) or its oxidized derivative $\mathbf{2}$ (for $\mathbf{5}$ ) with corresponding alkynes in refluxing $\mathrm{CH}_{3} \mathrm{CN}$. This afforded target furano[2,3d]pyrimidine nucleosides in good yields (36-82\%). Such a deviation in yields was due both to the difference in alkyne structures and to the fact that isolation and purification of some products turned to be laborious. Subsequent treatment of compounds $\mathbf{3 a}-\mathbf{i}$ with $32 \%$ ammonia in methanol resulted in corresponding pyrrolo[2,3-d]pyrimidine analogs $4 \mathbf{a}-\mathbf{i}$ (Scheme 1). The reactions at $40{ }^{\circ} \mathrm{C}$ were rather slow, but such mild conditions gave us an opportunity to obtain products $4 \mathbf{a}-\mathbf{i}$ with good yields $(57-89 \%)$ without using a bomb. It is worth remarking that preparative liquid chromatography on silica gel plates turned to be more effective for the isolation of pyrrolo[2,3-d]pyrimidine analogues $4 \mathbf{a}-\mathbf{i}$ than the column chromatography on silica gel, which was our choice in the case of furano[2,3-d]pyrimidine derivatives $\mathbf{3 a - i}$ and $\mathbf{5}$. All the compounds were synthesized as racemic mixtures.

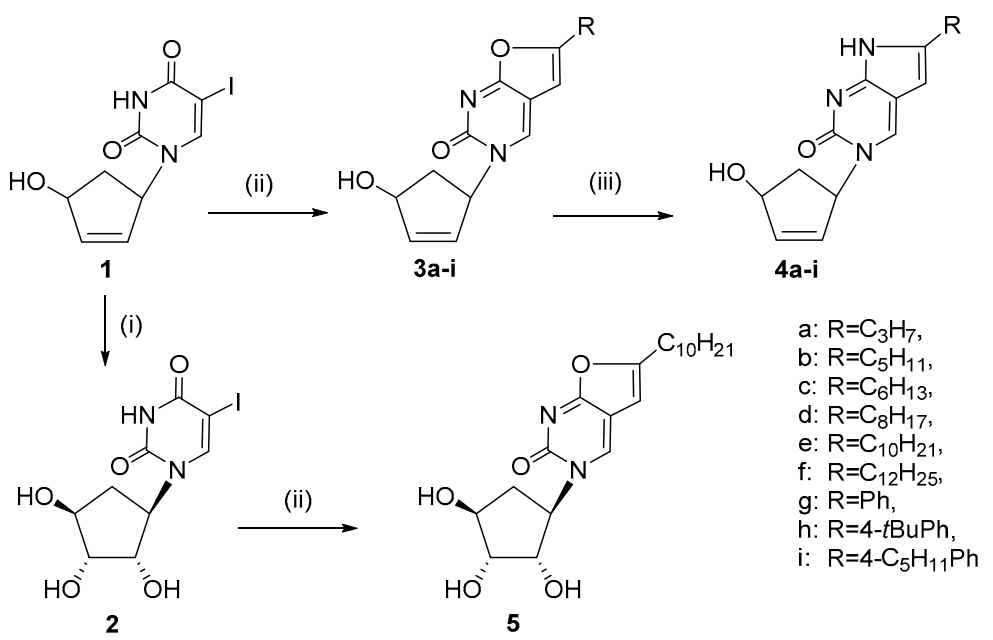

Scheme 1. Synthesis of the compounds. Reaction conditions: (i) $\mathrm{OsO}_{4}, \mathrm{NMMO}$; (ii) $\mathrm{CuI}, 10 \% \mathrm{Pd} / \mathrm{C}$, $\mathrm{RC} \equiv \mathrm{CH}, \mathrm{NEt}_{3}, \mathrm{CH}_{3} \mathrm{CN}$; (iii) $\mathrm{NH}_{3} / \mathrm{MeOH}$.

As a result, a set of novel bicyclic furano[2,3-d]pyrimidine nucleosides $3 \mathbf{a}-\mathbf{i}$, early unknown bicyclic pyrrolo[2,3-d]pyrimidine nucleosides $4 \mathbf{a}-\mathbf{i}$ and a new $1-\left(2^{\prime}, 3^{\prime}, 4^{\prime}\right.$-trihydroxycyclopent $1^{\prime}$ yl)6-decyl-3H-furano[2,3-d]pyrimidine-2-one 5 were obtained. The last one was synthesized as a first representative of trihydroxycyclopentyl derivatives of furano[2,3-d]pyrimidine-2-one in order to estimate the potential of this modification for antitumor activity and to gain a better structure activity relationship (SAR) understanding. 


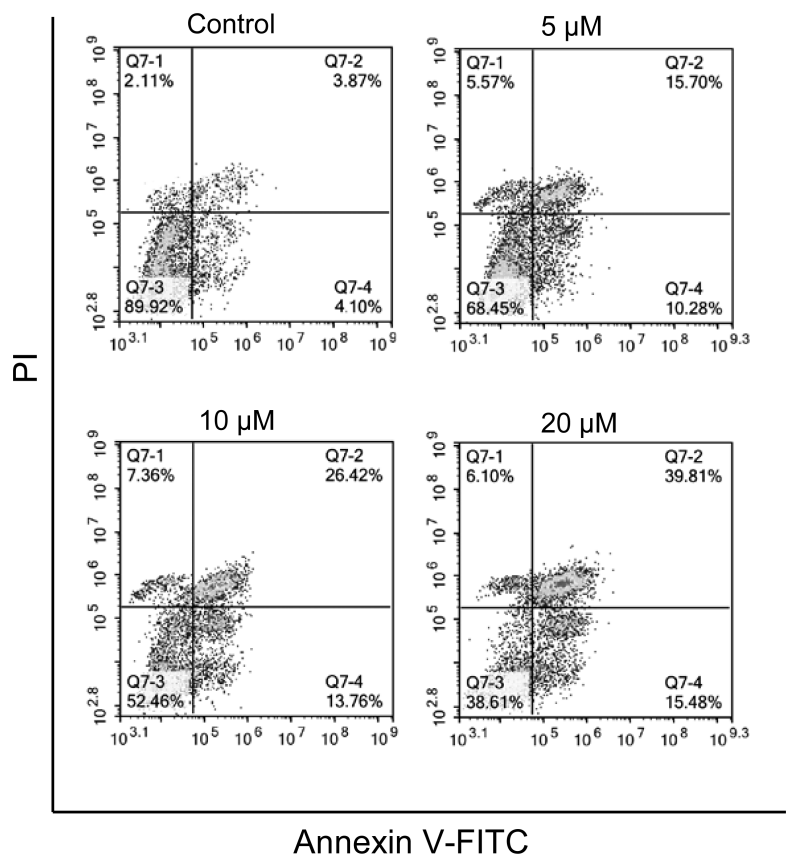

Figure 1. Quantification of apoptosis with annexin V binding to KB-3-1 cells. Cells were incubated in the presence of $3 \mathbf{i}(5,10$ or $20 \mu \mathrm{M})$, or in the presence of DMSO $(0.1 \% v / v)$ for $48 \mathrm{~h}$ and then Annexin $\mathrm{V} / \mathrm{PI}$ staining was analyzed by flow cytometry. Etoposide was used as a standard apoptosis inducer to confirm the correct work of the system (data not shown). The results of one of three independent experiments are represented.

\subsection{Biological Evaluation}

\subsubsection{Cell Viability Assay}

The target compounds were tested on different lines of tumor cells, HuTu-80 (human duodenal cancer), B16 (mouse melanoma), A549 (human lung adenocarcinoma), KB-3-1 (human squamous cell carcinoma), HeLa (human squamous cell carcinoma of the cervix), as well as on human noncancer cells hFF3.

Compounds $\mathbf{3} \mathbf{b}$ and $\mathbf{4 a}$ had no toxic effect on either normal untransfected hFF3 cells or on tumor cells in concentrations up to $100 \mu \mathrm{M}$. Compounds $\mathbf{3 d} \mathbf{d}-\mathbf{f}, \mathbf{h}$ and $\mathbf{4 f}, \mathbf{i}$ were almost equally toxic for cancer and noncancer cells (Table 1 ). The pyrrole-containing compounds $4 \mathbf{e}$ and $4 \mathrm{~h}$ were less toxic than the corresponding furan analogues $3 \mathbf{e}$ and $\mathbf{3 h}$, but also reduced the viability of all tested cell lines with $\mathrm{IC}_{50}$ in the range from $11 \mu \mathrm{M}$ (HeLa) to $63 \mu \mathrm{M}$ (hFF3) for 4e and from $15 \mu \mathrm{M}$ (KB-3-1) to $70 \mu \mathrm{M}$ (hFF3) for $4 \mathrm{~h}$. First $2^{\prime}, 3^{\prime}$-dihydroxy derivative 5, proved to be less toxic than the corresponding $2^{\prime}, 3^{\prime}$-didehydro-2' $3^{\prime}$-dideoxy analogue $3 \mathbf{e}$. Compounds $\mathbf{3 a}, \mathbf{3 c}, \mathbf{3 g}, \mathbf{3 i}, \mathbf{4 b}-\mathbf{d}, \mathbf{4 g}$ and 5 inhibited the growth of some tested tumor cells, mainly KB-3-1 and HeLa (Table 1), while they were not toxic for normal cells in concentrations up to $100 \mu \mathrm{M}$. Melanoma cells B16 were the most resistant towards action of these new nucleoside analogues. Only compounds $3 \mathbf{f}, 3 \mathbf{i}, 4 \mathbf{e}, 4 \mathbf{h}$ and $4 \mathbf{i}$ had the selective toxic effect on this line with $\mathrm{IC}_{50} 4.5,21,25,35$ and $13.4 \mu \mathrm{M}$, respectively.

The nucleoside analogue $3 \mathbf{i}$ was among most active compounds (Table 1) and had the most selective antiproliferative antitumor effect, especially against the HuTu80, KB-3-1 and HeLa cell lines (Table 2). Therefore, we used it as a lead compound to study the mechanism of induced cells death. 
Table 1. Antiproliferative activity of the compounds, $\mathrm{IC}_{50}(\mu \mathrm{M})$.

\begin{tabular}{|c|c|c|c|c|c|c|c|}
\hline & & $3 a-i$ & $4 a-i$ & 5 & & & \\
\hline Compound & $\mathbf{R}$ & HuTu80 & B16 & A549 & KB-3-1 & HeLa & hHFF3 \\
\hline $\begin{array}{l}3 a \\
4 a\end{array}$ & $\mathrm{C}_{3} \mathrm{H}_{7}$ & $\begin{array}{l}>100 \\
>100\end{array}$ & $\begin{array}{l}>100 \\
>100\end{array}$ & $\begin{array}{l}>100 \\
>100\end{array}$ & $\begin{array}{c}40.1 \pm 5.2 \\
\quad>100\end{array}$ & $\begin{array}{c}63.4 \pm 6.8 \\
>100\end{array}$ & $\begin{array}{l}>100 \\
>100\end{array}$ \\
\hline $\begin{array}{l}3 b \\
4 b\end{array}$ & $\mathrm{C}_{5} \mathrm{H}_{11}$ & $\begin{array}{c}>100 \\
80.4 \pm 0.9\end{array}$ & $\begin{array}{l}>100 \\
>100\end{array}$ & $\begin{array}{c}>100 \\
45.3 \pm 3.9\end{array}$ & $\begin{array}{c}>100 \\
25.2 \pm 3.4\end{array}$ & $\begin{array}{c}>100 \\
50.1 \pm 4.7\end{array}$ & $\begin{array}{l}>100 \\
>100\end{array}$ \\
\hline $\begin{array}{l}3 c \\
4 c\end{array}$ & $\mathrm{C}_{6} \mathrm{H}_{13}$ & $\begin{array}{c}100 \\
20.4 \pm 3.9\end{array}$ & $\begin{array}{l}>100 \\
>100\end{array}$ & $\begin{array}{l}50.3 \pm 6.1 \\
35.2 \pm 4.1\end{array}$ & $\begin{array}{l}45.3 \pm 5.1 \\
25.6 \pm 2.9\end{array}$ & $\begin{array}{c}>100 \\
50.7 \pm 6.2\end{array}$ & $\begin{array}{l}>100 \\
>100\end{array}$ \\
\hline $\begin{array}{l}3 d \\
4 d\end{array}$ & $\mathrm{C}_{8} \mathrm{H}_{17}$ & $\begin{array}{l}46.3 \pm 5.7 \\
30.2 \pm 2.9\end{array}$ & $\begin{array}{c}46.2 \pm 3.4 \\
>100\end{array}$ & $\begin{array}{c}54.1 \pm 6.1 \\
100\end{array}$ & $\begin{array}{l}47.3 \pm 4.2 \\
25.4 \pm 3.1\end{array}$ & $\begin{array}{l}40.6 \pm 3.9 \\
20.1 \pm 1.9\end{array}$ & $\begin{array}{c}48.2 \pm 5.1 \\
\quad>100\end{array}$ \\
\hline $\begin{array}{l}3 e \\
4 e\end{array}$ & $\mathrm{C}_{10} \mathrm{H}_{21}$ & $\begin{array}{c}7.3 \pm 2.4 \\
23.4 \pm 7.8\end{array}$ & $\begin{array}{l}21.3 \pm 3.1 \\
25.1 \pm 2.4\end{array}$ & $\begin{array}{c}36.2 \pm 11.3 \\
36.2 \pm 6.2\end{array}$ & $\begin{array}{l}11.2 \pm 5.3 \\
18.4 \pm 7.1\end{array}$ & $\begin{array}{l}4.5 \pm 0.9 \\
11 \pm 2.1\end{array}$ & $\begin{array}{l}11.6 \pm 2.1 \\
62.5 \pm 8.3\end{array}$ \\
\hline $\begin{array}{l}3 f \\
4 f\end{array}$ & $\mathrm{C}_{12} \mathrm{H}_{25}$ & $\begin{array}{l}7.1 \pm 0.8 \\
3.1 \pm 0.4\end{array}$ & $\begin{array}{l}4.5 \pm 0.3 \\
3.1 \pm 0.3\end{array}$ & $\begin{array}{c}10.5 \pm 1.9 \\
4.5 \pm 0.2\end{array}$ & $\begin{array}{c}10.2 \pm 4.1 \\
4.5 \pm 0.9\end{array}$ & $\begin{array}{l}2.5 \pm 0.3 \\
3.2 \pm 0.4\end{array}$ & $\begin{array}{c}10.2 \pm 1.8 \\
3.4 \pm 0.7\end{array}$ \\
\hline $\begin{array}{l}3 g \\
4 g\end{array}$ & $\mathrm{Ph}$ & $\begin{array}{l}>100 \\
>100\end{array}$ & $\begin{array}{l}>100 \\
>100\end{array}$ & $\begin{array}{c}>100 \\
50.2 \pm 6.7\end{array}$ & $\begin{array}{l}30.1 \pm 4.1 \\
45.4 \pm 5.3\end{array}$ & $\begin{array}{l}45.3 \pm 5.1 \\
90.2 \pm 9.6\end{array}$ & $\begin{array}{l}>100 \\
>100\end{array}$ \\
\hline $\begin{array}{l}3 \mathrm{~h} \\
4 \mathrm{~h}\end{array}$ & 4-tBuPh & $\begin{array}{c}9.9 \pm 1.7 \\
25.4 \pm 3.1\end{array}$ & $\begin{array}{l}10.1 \pm 2.3 \\
35.6 \pm 4.2\end{array}$ & $\begin{array}{c}7.2 \pm 0.8 \\
25.3 \pm 2.9\end{array}$ & $\begin{array}{c}1.7 \pm 0.2 \\
15.3 \pm 1.1\end{array}$ & $\begin{array}{c}2.3 \pm 0.3 \\
25.8 \pm 4.6\end{array}$ & $\begin{array}{c}5.1 \pm 0.7 \\
70.9 \pm 9.1\end{array}$ \\
\hline $\begin{array}{l}3 i \\
4 i\end{array}$ & $4-\mathrm{C}_{5} \mathrm{H}_{11} \mathrm{Ph}$ & $\begin{array}{l}5.1 \pm 0.6 \\
8.5 \pm 1.1\end{array}$ & $\begin{array}{l}21.3 \pm 2.9 \\
13.4 \pm 3.2\end{array}$ & $\begin{array}{l}47.5 \pm 5.8 \\
15.6 \pm 4.1\end{array}$ & $\begin{array}{l}8.2 \pm 1.3 \\
9.8 \pm 0.7\end{array}$ & $\begin{array}{c}6.5 \pm 0.9 \\
11.1 \pm 0.9\end{array}$ & $\begin{array}{c}>100 \\
21.9 \pm 4.8\end{array}$ \\
\hline 5 & $\mathrm{C}_{10} \mathrm{H}_{21}$ & $>100$ & $>100$ & $>100$ & $50.3 \pm 9.8$ & $70.2 \pm 8.9$ & $>100$ \\
\hline
\end{tabular}

Table 2. Selectivity index of the tested compounds.

\begin{tabular}{|c|c|c|c|c|c|c|}
\hline Compound & $\mathbf{R}$ & HuTu80 & B16 & A549 & KB-3-1 & HeLa \\
\hline $3 a$ & \multirow{2}{*}{$\mathrm{C}_{3} \mathrm{H}_{7}$} & 1 & 1 & 1 & $>2.5$ & $>1.6$ \\
\hline $4 a$ & & 1 & 1 & 1 & 1 & 1 \\
\hline $3 b$ & \multirow{2}{*}{$\mathrm{C}_{5} \mathrm{H}_{11}$} & 1 & 1 & 1 & 1 & 1 \\
\hline $4 b$ & & $>1.2$ & 1 & $>2.2$ & $>3.9$ & $>1.9$ \\
\hline $3 c$ & \multirow{2}{*}{$\mathrm{C}_{6} \mathrm{H}_{13}$} & 1 & 1 & $>1.9$ & $>2.2$ & 1 \\
\hline $4 c$ & & $>4.9$ & 1 & $>2.8$ & $>3.9$ & $>1.9$ \\
\hline $3 d$ & \multirow{2}{*}{$\mathrm{C}_{8} \mathrm{H}_{17}$} & 1 & 1 & 0.9 & 1 & 1.2 \\
\hline $4 d$ & & $>3.3$ & 1 & 1 & $>3.9$ & $>4.9$ \\
\hline $3 e$ & \multirow{2}{*}{$\mathrm{C}_{10} \mathrm{H}_{21}$} & 1.6 & 0.5 & 0.3 & 1 & 2.6 \\
\hline $4 e$ & & 2.6 & 2.5 & 1.7 & 3.4 & 5.7 \\
\hline $3 f$ & \multirow{2}{*}{$\mathrm{C}_{12} \mathrm{H}_{25}$} & 1.4 & 2.3 & 1 & 1 & 4.1 \\
\hline $4 \mathrm{f}$ & & 1.1 & 1.1 & 0.8 & 0.8 & 1 \\
\hline $3 g$ & \multirow[b]{2}{*}{$\mathrm{Ph}$} & 1 & 1 & 1 & $>3.3$ & $>2.2$ \\
\hline $4 \mathrm{~g}$ & & 1 & 1 & $>2$ & $>2.2$ & $>1.1$ \\
\hline $3 h$ & \multirow{2}{*}{ 4-tBuPh } & 0.5 & 0.5 & 0.7 & 3 & 2.2 \\
\hline $4 h$ & & 2.8 & 1.9 & 2.8 & 4.6 & 2.7 \\
\hline
\end{tabular}


Table 2. Cont.

\begin{tabular}{ccccccc}
\hline Compound & $\mathbf{R}$ & HuTu80 & B16 & A549 & KB-3-1 & HeLa \\
\hline $3 \mathbf{i}$ & \multirow{2}{*}{$4-\mathrm{C}_{5} \mathrm{H}_{11} \mathrm{Ph}$} & $>\mathbf{1 9 . 6}$ & $>4.7$ & $>2.1$ & $>\mathbf{1 2 . 2}$ & $>\mathbf{1 5 . 3}$ \\
$\mathbf{4} \mathbf{n}$ & & 2.6 & 1.6 & 1.4 & 2.2 & 1.9 \\
\hline $\mathbf{5}$ & $\mathrm{C}_{10} \mathrm{H}_{21}$ & 1 & 1 & 1 & $>2$ & $>1.4$ \\
\hline
\end{tabular}

The selectivity index (SI) was the ratio of $\mathrm{IC}_{\mathrm{hFF} 3}$ (cytotoxicity on normal hFF3 cells) to $\mathrm{IC}_{50}$ of cancer cells.

\subsubsection{Induction of Apoptosis}

To examine whether the tested $5^{\prime}$-norcarbocyclic derivatives induce cell death via apoptosis Annexin V and propidium iodide analysis were used (Figure 1). KB-3-1 cells were exposed to 3i, the most active among tested compounds, for $48 \mathrm{~h}$ and then flow cytometric analysis was undertaken. Annexin $\mathrm{V}$ binds phosphatidylserine residues, which are asymmetrically distributed toward the inner plasma membrane, and migrate to the outer plasma membrane during apoptosis [17]. The data shows that $3 \mathbf{i}$ induces apoptotic cell death in $26 \%$ of KB-3-1 cells at concentrations of $5 \mu \mathrm{M}$. The increasing of $3 \mathbf{i}$ concentration to $20 \mu \mathrm{M}$ resulted in $55.3 \%$ apoptotic cells after $48 \mathrm{~h}$ of incubation of KB-3-1 cells with the analogue. Hence, the $5^{\prime}$-norcarbocyclic derivative $3 \mathbf{i}$ induced dose-dependent apoptotic cell death.

We next investigated whether $3 \mathbf{i}$ utilizes the mitochondrial 'intrinsic' pathway in the apoptotic death of KB-3-1 cells, since the pivotal role of mitochondria in triggering apoptosis is well established. We evaluated the mitochondrial transmembrane potential $\left(\Delta \Psi_{m}\right)$ in KB-3-1 cells exposed to 3i using cytofluorometric analysis. Cells were stained with the specific mitochondrial cationic dye JC-1 (5,5',6,6'-tetrachloro-1,1',3,3'-tetraethyl benzimidazole carbocyanine iodide) that accumulates in the transmembrane space of polarized mitochondria and forms the so-called «J-aggregates», emitting red fluorescence. A decrease in $\Delta \Psi_{\mathrm{m}}$ results in disappearance of J-aggregates and formation of JC-1 monomers, which emit in a green fluorescence. The cytometric analysis of KB-3-1 cells stained with JC-1 is shown in Figure 2.

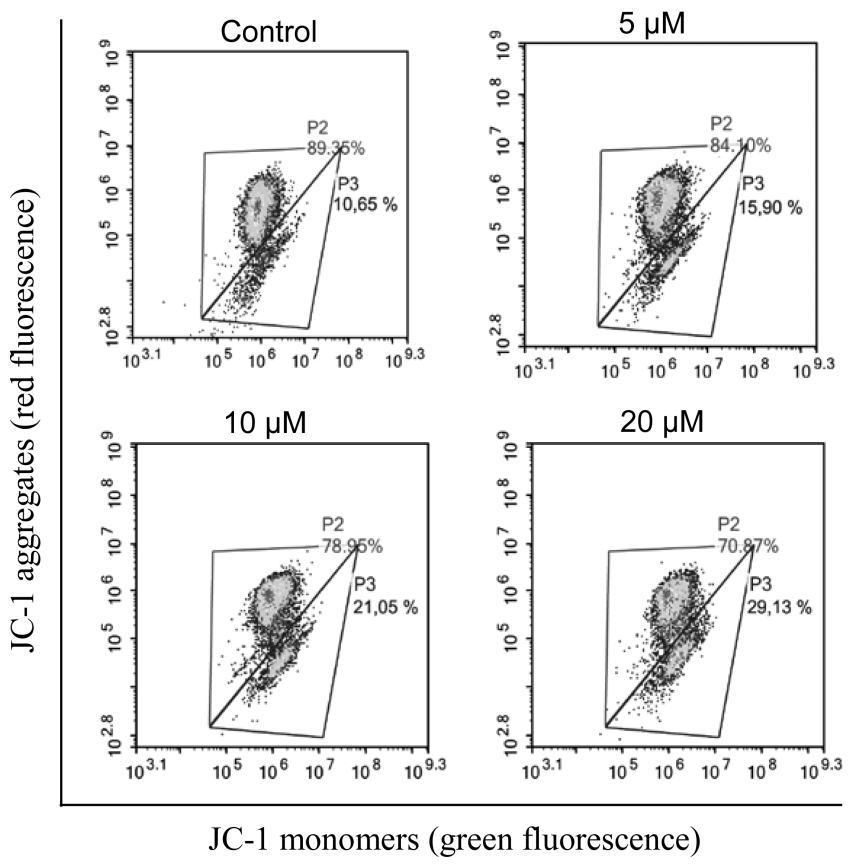

Figure 2. Analysis of mitochondrial transmembrane potential of KB-3-1 cells treated with the compound $3 \mathbf{i}$ by flow cytometry after JC- 1 staining. Cells were incubated with $3 \mathbf{i}(5,10$ or $20 \mu \mathrm{M})$ or DMSO $(0.1 \%$ $v / v$ ) for $48 \mathrm{~h}$. In normal cells, the dye is aggregated in mitochondria, and fluoresces red. In cells with altered mitochondrial potential, the dye fails to accumulate in the mitochondria, remained as monomers in the cytoplasm, and fluoresces green. 
In the control cells incubated in the presence of $0.1 \%$ DMSO the majority of cells shows a high emission of fluorescence in both channels due to the equilibrium between J-aggregates and monomers (Figure 2). The exposure of KB-3-1 cells to $20 \mu \mathrm{M}$ of compound $3 \mathbf{i}$ leads to a decrease of the red fluorescence value as compared to the control (0.1\% DMSO).

\section{Materials and Methods}

\subsection{Chemistry}

$N$-Methylmorpholine- $N$-oxide (NMMO), peracetic acid, $\mathrm{Pd}\left(\mathrm{PPh}_{3}\right)_{4}, \mathrm{CuI}, 10 \% \mathrm{Pd} / \mathrm{C}$, triethylamine, 3-(4,5-dimethylthiazol-2-yl)-2,5-diphenyltetrazolium bromide, propidium iodide and organic solvents were obtained from "Acros" (Belgium) or "Aldrich" (USA) and were used without further purification. 1-(4'-Hydroxy-2'-cyclopenten-1'-yl)-5-iodouracil (1) was synthesized according an earlier published protocol [12]; 1-(4'-hydroxy-2'-cyclopenten-1'-yl)-6-octyl-3Hfurano[2,3-d]-pyrimidine-2-one (3d), 1-(4'-hydroxy-2'-cyclopenten-1'-yl)-6-decyl-3Hfurano[2,3-d]-pyrimidine-2-one (3e) and 1-(4'-hydroxy2'-cyclopenten-1'-yl)-6-dodecyl-3Hfurano[2,3-d]-pyrimidine-2-one (3f) were prepared as described earlier [12,13]. Annexin-FITC apoptosis staining/detection kit was from "Abcam" (Eugene, CA USA); 5,5',6,6'-tetrachloro-1,1',3,3'tetraethylbenzimidazolylcarbocyanine iodide (JC-1) was from "Invitrogen" (San Diego, CA, USA).

Column chromatography was performed on Silica Gel 60 0.040-0.063 mm (Merck, Germany), and systems for elution are indicated in the text. Thin layer chromatography (TLC) was performed on TLC Silica gel $60 \mathrm{~F}_{254}$ plates (Merck, Germany) in chloroform-methanol, 9:1 (A), or chloroform-methanol, 4:1 (B) systems. Preparative layer chromatography (PLC) was performed on PLC Silica gel $60 \mathrm{~F}_{254}$ plates (Merck, Germany), systems for elution are indicated in the text.

${ }^{1} \mathrm{H}$ and ${ }^{13} \mathrm{C}$ nuclear magnetic resonance (NMR) spectra were registered on a Bruker Avance 400 spectrometer (Bruker, Newark, Germany) using tetramethylsilane (TMS) in $\mathrm{CDCl}_{3}, \mathrm{CD}_{3} \mathrm{OD}$, $\mathrm{CDCl}_{3} / \mathrm{CD}_{3} \mathrm{OD}$ mixture, or DMSO- $d_{6}$ as internal standard. Chemical shifts are given in ppm, and the letter " $J$ " indicates normal ${ }^{3} J_{\mathrm{HH}}$ couplings and all $J$ values are given in $\mathrm{Hz}$.

High-resolution mass spectra (HRMS) were registered on a Bruker Daltonics micrOTOF-Q II instrument using electrospray ionization (ESI). The measurements were acquired in a negative ion mode with the following parameters: interface capillary voltage-3700 V; mass range from $\mathrm{m} / z 50$ to 3000; external calibration (Electrospray Calibrant Solution, Fluka); nebulizer pressure-0.3 Bar; flow rate $-3 \mu \mathrm{L} / \mathrm{min}$; dry gas nitrogen $(4.0 \mathrm{~L} / \mathrm{min})$; interface temperature was set at 180 or $190{ }^{\circ} \mathrm{C}$. A syringe injection was used.

The absorbance (MTT assay) was measured on a plate reader Multiscan RC (Thermo LabSystems, Vantaa, Finland) at $570 \mathrm{~nm}$. Mitochondrial transmembrane potential and the amount of apoptotic cells in samples were analyzed by flow cytometer «FC500» (Beckman Coulter, Indianapolis, IN, USA).

3.1.1. General Method for the Synthesis of

1-(4'-hydroxy-2'-cyclopenten-1'-yl)-6-alkyl-3H-furano[2,3-d]pyrimidine-2-ones and 1-(4'-hydroxy-2' -cyclopenten-1'-yl)-6-aryl-3H-furano[2,3-d]-pyrimidine-2-ones (3a-i)

To the solution of 1-(4'-hydroxy-2'-cyclopenten-1'-yl)-5-iodouracil (100 mg, $0.31 \mathrm{mmol})$ in acethonitrile $(5 \mathrm{~mL}) \mathrm{CuI}(19 \mathrm{mg}, 0.1 \mathrm{mmol}), 10 \% \mathrm{Pd} / \mathrm{C}(15 \mathrm{mg})$ and appropriate 1 -alkyne $(0.38 \mathrm{mmol})$ were added and the reaction mixture was refluxed for $4 \mathrm{~h}$. The progress of the reaction was monitored by TLC. Reaction mixtures were evaporated to dryness in vacuo, the residues were dissolved in the appropriate solvent mixture and $3 \mathbf{a}-\mathbf{i}$ were isolated and purified using column chromatography on silica gel.

1-(4'-Hydroxy-2'-cyclopenten-1'-yl)-6-propyl-3H-furano[2,3-d]-pyrimidine-2-one (3a) was purified on a silica gel column using chloroform: methanol (97:3) as an eluent with $41 \%$ yield. $\mathrm{R}_{f} 0.35$ (system A). ${ }^{1} \mathrm{H}-\mathrm{NMR}$ (CD $3 \mathrm{OD}): 8.29$ (1H, s, H4), 6.39 (1H, m, H5), 6.34-6.31 (1H, m, H2' ), 6.00-5.97 (1H, m, H3' ), 5.77-5.75 (1H, $\left.\mathrm{m}, \mathrm{H1}^{\prime}\right), 4.87-4.82\left(1 \mathrm{H}, \mathrm{m}, \mathrm{H} 4^{\prime}\right), 3.07-3.02\left(1 \mathrm{H}, \mathrm{m}, \mathrm{H} 5^{\prime} \mathrm{a}\right), 2.71-2.66\left(2 \mathrm{H}, \mathrm{m}, \underline{\mathrm{CH}_{2}} \mathrm{CH}_{2} \mathrm{CH}_{3}\right), 1.81-1.69$ (2H, 
$\left.\mathrm{m}, \mathrm{CH}_{2} \mathrm{CH}_{2} \mathrm{CH}_{3}\right), 1.59-1.52\left(1 \mathrm{H}, \mathrm{m}, \mathrm{H} 5{ }^{\prime} \mathrm{b}\right), 1.03\left(3 \mathrm{H}, \mathrm{t}, J=8 \mathrm{~Hz}, \mathrm{CH}_{2} \mathrm{CH}_{2} \mathrm{CH}_{3}\right) .{ }^{13} \mathrm{C}-\mathrm{NMR}\left(\mathrm{CD}_{3} \mathrm{OD}\right)$ : 172.4, 160.9, 157.2, 141.1, 139.2, 131.8, 109.7, 100.2, 75.1, 63.2, 41.9, 30.5, 20.9, 13.4. HRMS (ESI, $m / z$ ) of $\mathrm{C}_{14} \mathrm{H}_{16} \mathrm{~N}_{2} \mathrm{O}_{3}$ : calcd. for $[\mathrm{M}+\mathrm{Na}]^{+} 283.1053$, found 283.1061 , see Supplementary Materials.

1-(4'-Hydroxy-2'-cyclopenten-1'-yl)-6-pentyl-3H-furano[2,3-d]-pyrimidine-2-one (3b) was purified on silica gel column using chloroform: methanol (98:2 to $95: 5)$ as an eluent with $69 \%$ yield. $\mathrm{R}_{f} 0.36$ (system A). ${ }^{1} \mathrm{H}-\mathrm{NMR}\left(\mathrm{CD}_{3} \mathrm{OD}\right): 8.29(1 \mathrm{H}, \mathrm{s}, \mathrm{H} 4), 6.38(1 \mathrm{H}, \mathrm{m}, \mathrm{H} 5), 6.35-6.31\left(1 \mathrm{H}, \mathrm{m}, \mathrm{H2}{ }^{\prime}\right), 6.00-5.97(1 \mathrm{H}, \mathrm{m}$, $\left.\mathrm{H}^{\prime}\right), 5.81-5.75\left(1 \mathrm{H}, \mathrm{m}, \mathrm{H} 1^{\prime}\right), 4.87-4.82\left(1 \mathrm{H}, \mathrm{m}, \mathrm{H} 4^{\prime}\right), 3.05-3.00\left(1 \mathrm{H}, \mathrm{m}, \mathrm{H} 5^{\prime} \mathrm{a}\right), 2.71(2 \mathrm{H}, \mathrm{t}, J=8 \mathrm{~Hz}$, $\left.\mathrm{CH}_{2} \mathrm{CH}_{2}\left(\mathrm{CH}_{2}\right)_{2} \mathrm{CH}_{3}\right), 1.75-1.70\left(2 \mathrm{H}, \mathrm{m}, \mathrm{CH}_{2} \mathrm{CH}_{2}\left(\mathrm{CH}_{2}\right)_{2} \mathrm{CH}_{3}\right), 1.59-1.52\left(1 \mathrm{H}, \mathrm{m}, \mathrm{H} 5^{\prime} \mathrm{b}\right), 1.43-1.37(4 \mathrm{H}$, $\left.\mathrm{m}, \mathrm{CH}_{2} \mathrm{CH}_{2}\left(\mathrm{CH}_{2}\right)_{2} \mathrm{CH}_{3}\right), 0.94\left(3 \mathrm{H}, \mathrm{t}, J=8 \mathrm{~Hz}, \mathrm{CH}_{2} \mathrm{CH}_{2}\left(\mathrm{CH}_{2}\right)_{2} \mathrm{CH}_{3}\right) .{ }^{13} \mathrm{C}-\mathrm{NMR}\left(\mathrm{CD}_{3} \mathrm{OD}\right):$ 171.4, 160.1, $156.3,140.1,138.2,130.8,108.7,99.1,74.1,62.2,40.9,30.9,27.5,26.3,21.9,12.8$. HRMS (ESI, $m / z)$ of $\mathrm{C}_{16} \mathrm{H}_{20} \mathrm{~N}_{2} \mathrm{O}_{3}$ : calcd. for $[\mathrm{M}+\mathrm{H}]^{+}$289.1547, found 289.1545.

1-(4'-Hydroxy-2'-cyclopenten-1'-yl)-6-hexyl-3H-furano[2,3-d]-pyrimidine-2-one (3c) was purified using two-step chromatography on silica gel. The first column was eluted with chloroform: methanol (98:2 to 95:5) and the second one with hexane: ethyl acetate (1:4) to ethyl acetate: methanol (97:3) as an eluent to give (3c) with $52 \%$ yield. $\mathrm{R}_{f} 0.36$ (system A). ${ }^{1} \mathrm{H}-\mathrm{NMR}\left(\mathrm{CD}_{3} \mathrm{OD}\right): 8.27(1 \mathrm{H}, \mathrm{s}, \mathrm{H} 4)$, $6.36(1 \mathrm{H}, \mathrm{s}, \mathrm{H} 5), 6.32-6.30\left(1 \mathrm{H}, \mathrm{m}, \mathrm{H} 2^{\prime}\right), 5.98-5.96\left(1 \mathrm{H}, \mathrm{m}, \mathrm{H3}^{\prime}\right), 5.76-5.75\left(1 \mathrm{H}, \mathrm{m}, \mathrm{H1}{ }^{\prime}\right), 4.85-4.83$ $\left(1 \mathrm{H}, \mathrm{m}, \mathrm{H} 4^{\prime}\right), 3.05-3.01\left(1 \mathrm{H}, \mathrm{m}, \mathrm{H} 5^{\prime} \mathrm{a}\right), 2.69\left(2 \mathrm{H}, \mathrm{t}, J=8 \mathrm{~Hz}, \mathrm{CH}_{2} \mathrm{CH}_{2}\left(\mathrm{CH}_{2}\right)_{3} \mathrm{CH}_{3}\right), 1.76-1.68(2 \mathrm{H}, \mathrm{m}$, $\left.\mathrm{CH}_{2} \mathrm{CH}_{2}\left(\mathrm{CH}_{2}\right)_{3} \mathrm{CH}_{3}\right), 1.56-1.51\left(1 \mathrm{H}, \mathrm{m}, \mathrm{H} 5^{\prime} \mathrm{b}\right), 1.35-1.29\left(6 \overline{\mathrm{H}}, \mathrm{m}, \mathrm{CH}_{2} \mathrm{CH}_{2}\left(\mathrm{CH}_{2}\right)_{3} \mathrm{CH}_{3}\right), 0.92(3 \mathrm{H}, \mathrm{t}$, $\left.J=8 \overline{\mathrm{Hz}}, \mathrm{CH}_{2} \mathrm{CH}_{2}\left(\mathrm{CH}_{2}\right)_{3} \mathrm{CH}_{3}\right) .{ }^{13} \mathrm{C}-\mathrm{NMR}\left(\mathrm{CD}_{3} \mathrm{OD}\right): 172.8,161.5,157.7,141.5,139.6,132.2,110.1,100.5$, 75.5, 63.6, 42.3, 32.6, 29.7, 29.0, 28.0, 23.6, 14.3. HRMS (ESI, $m / z$ ) of $\mathrm{C}_{17} \mathrm{H}_{22} \mathrm{~N}_{2} \mathrm{O}_{3}$ : calcd. for $[\mathrm{M}+\mathrm{H}]^{+}$ 303.1703, found 303.1698.

1-(4'-Hydroxy-2'-cyclopenten-1'-yl)-6-phenyl-3H-furano[2,3-d]-pyrimidine-2-one (3g) was purified using column chromatography with chloroform: methanol (97:3) as an eluent and then on a PLC in ethyl acetate with $37 \%$ yield. $\mathrm{R}_{f} 0.34$ (system A). ${ }^{1} \mathrm{H}-\mathrm{NMR}\left(\mathrm{CDCl}_{3}-\mathrm{CD}_{3} \mathrm{OD}\right): 8.17(1 \mathrm{H}, \mathrm{s}, \mathrm{H} 4), 7.71-7.69(2 \mathrm{H}$, $\mathrm{m}, \mathrm{Ph}), 7.41-7.32(3 \mathrm{H}, \mathrm{m}, \mathrm{Ph}), 6.69(1 \mathrm{H}, \mathrm{s}, \mathrm{H} 5), 6.27-6.26\left(1 \mathrm{H}, \mathrm{m}, \mathrm{H2}{ }^{\prime}\right), 5.87-5.86\left(1 \mathrm{H}, \mathrm{m}, \mathrm{H}^{\prime}\right), 5.81-5.80$ $\left(1 \mathrm{H}, \mathrm{m}, \mathrm{H} 1^{\prime}\right), 4.85-4.83\left(1 \mathrm{H}, \mathrm{m}, \mathrm{H} 4^{\prime}\right), 3.01-2.94\left(1 \mathrm{H}, \mathrm{m}, \mathrm{H} 5^{\prime} \mathrm{a}\right), 1.60-1.56\left(1 \mathrm{H}, \mathrm{m}, \mathrm{H} 5^{\prime} \mathrm{b}\right) .{ }^{13} \mathrm{C}-\mathrm{NMR}$ $\left(\mathrm{CDCl}_{3}-\mathrm{CD}_{3} \mathrm{OD}\right): 171.3,156.0,140.2,138.4,131.7,129.80,129.0 \times 2,128.3,125.0 \times 2,109.1,97.7,74.4$, 62.4, 41.1, 29.7. HRMS (ESI, $m / z$ ) of $\mathrm{C}_{17} \mathrm{H}_{14} \mathrm{~N}_{2} \mathrm{O}_{3}$ : calcd. for $[\mathrm{M}+\mathrm{H}]^{+} 295.1077$, found 295.1077.

1-(4'-Hydroxy-2'-cyclopenten-1'-yl)-6-tertbutylphenyl-3H-furano[2,3-d]-pyrimidine-2-one (3h) was purified on a silica gel column using chloroform: methanol (98:2) as an eluent with $36 \%$ yield. $\mathrm{R}_{f} 0.36$ (system A). ${ }^{1} \mathrm{H}-\mathrm{NMR}\left(\mathrm{CDCl}_{3}-\mathrm{CD}_{3} \mathrm{OD}\right): 8.14(1 \mathrm{H}, \mathrm{s}, \mathrm{H} 4), 7.63(2 \mathrm{H}, \mathrm{d}, J=8 \mathrm{~Hz}, \mathrm{Ph}), 7.41(2 \mathrm{H}, \mathrm{d}, J=8 \mathrm{~Hz}, \mathrm{Ph})$, $6.63(1 \mathrm{H}, \mathrm{s}, \mathrm{H} 5), 6.26\left(1 \mathrm{H}, \mathrm{m}, \mathrm{H} 2^{\prime}\right), 5.86\left(1 \mathrm{H}, \mathrm{m}, \mathrm{H} 3^{\prime}\right), 5.80\left(1 \mathrm{H}, \mathrm{m}, \mathrm{H} 1^{\prime}\right), 4.84\left(1 \mathrm{H}, \mathrm{m}, \mathrm{H} 4^{\prime}\right), 3.01-2.93$ $\left(1 \mathrm{H}, \mathrm{m}, \mathrm{H}^{\prime} \mathrm{a}\right), 1.61-1.57\left(1 \mathrm{H}, \mathrm{m}, \mathrm{H} 5^{\prime} \mathrm{b}\right), 1.28$ (9H, s, tBu). ${ }^{13} \mathrm{C}-\mathrm{NMR}\left(\mathrm{CDCl}_{3}-\mathrm{CD}_{3} \mathrm{OD}\right): 171.3,156.2,155.9$, 153.4, 140.1, 137.9, 131.7, $125.9 \times 2,125.5,124.8 \times 2,109.2,96.9,74.4,62.3,41.2,34.9,31.1 \times 3$. HRMS (ESI, $m / z$ ) of $\mathrm{C}_{21} \mathrm{H}_{22} \mathrm{~N}_{2} \mathrm{O}_{3}$ : calcd. for $[\mathrm{M}+\mathrm{H}]^{+}$351.1703, found 351.1698.

1-(4'-Hydroxy-2'-cyclopenten-1'-yl)-6-(4-pentylphenyl)-3H-furano[2,3-d]-pyrimidine-2-one (3i) was purified using two-step chromatography on silica gel. The first column was eluted with chloroform: methanol (98:2 to 97:3) and the second one with hexane: ethyl acetate (1:4) to ethyl acetate: methanol (97:3) as an eluent to give (3i) with $82 \%$ yield. $\mathrm{R}_{f} 0.36$ (system A). ${ }^{1} \mathrm{H}-\mathrm{NMR}\left(\mathrm{CDCl}_{3}-\mathrm{CD}_{3} \mathrm{OD}\right): 8.33(1 \mathrm{H}$, $\mathrm{s}$, $\mathrm{H} 4), 7.68(2 \mathrm{H}, \mathrm{d}, J=8.5 \mathrm{~Hz}, \mathrm{Ph}), 7.27(2 \mathrm{H}, \mathrm{d}, J=8.5 \mathrm{~Hz}, \mathrm{Ph}), 6.84(1 \mathrm{H}, \mathrm{s}, \mathrm{H} 5), 6.35-6.32\left(1 \mathrm{H}, \mathrm{m}, \mathrm{H} 2^{\prime}\right)$, 5.95-5.93 (1H, m, H3' $), 5.85-5.82\left(1 \mathrm{H}, \mathrm{m}, \mathrm{H1} 1^{\prime}\right), 4.88-4.86\left(1 \mathrm{H}, \mathrm{m}, \mathrm{H} 4^{\prime}\right), 3.07-3.00$ (1H, m, H5' a), 2.65 $\left(2 \mathrm{H}, \mathrm{t}, J=9 \mathrm{~Hz}, \mathrm{CH}_{2} \mathrm{CH}_{2}\left(\mathrm{CH}_{2}\right)_{2} \mathrm{CH}_{3}\right), 1.66-1.57\left(3 \mathrm{H}, \mathrm{m}, \mathrm{H} 5^{\prime} \mathrm{b}\right.$ and $\left.\mathrm{CH}_{2} \mathrm{CH}_{2}\left(\mathrm{CH}_{2}\right)_{2} \mathrm{CH}_{3}\right), 1.35-1.32(4 \mathrm{H}$, $\left.\mathrm{m}, \mathrm{CH}_{2} \mathrm{CH}_{2}\left(\mathrm{CH}_{2}\right)_{2} \mathrm{CH}_{3}\right), 0.89\left(3 \mathrm{H}, \mathrm{t}, J=9 \mathrm{~Hz}, \mathrm{CH}_{2} \mathrm{CH}_{2}\left(\mathrm{CH}_{2}\right)_{2} \mathrm{CH}_{3}\right) .{ }^{13} \mathrm{C}-\mathrm{NMR}\left(\mathrm{CDCl}_{3}-\mathrm{CD}_{3} \mathrm{OD}\right):$ : 171.1, 156.3 156.0, 145.0, 140.0, 138.4, 130.09, $128.8 \times 2,125.5,124.6 \times 2,109.5,96.8,73.9,62.1,41.9,35.4,31.1$, 30.6, 22.1, 13.3. HRMS (ESI, $m / z$ ) of $\mathrm{C}_{22} \mathrm{H}_{24} \mathrm{~N}_{2} \mathrm{O}_{3}$ : calcd. for $[\mathrm{M}+\mathrm{H}]^{+} 365.1861$, found 365.1860.

1-(2', $3^{\prime}, 4^{\prime}$-Trihydroxycyclopent1'-yl)-5-iodouracil (2) was synthesized using the common procedure [14] ${ }^{1} \mathrm{H}-\mathrm{NMR}\left(\mathrm{DMSO}-d_{6}\right): 11.58(1 \mathrm{H}, \mathrm{s}, \mathrm{NH}), 8.12(1 \mathrm{H}, \mathrm{s}, \mathrm{H6}), 5.14(1 \mathrm{H}, \mathrm{d}, J=4 \mathrm{~Hz}, \mathrm{OH}), 4.95(1 \mathrm{H}, \mathrm{d}, J=6 \mathrm{~Hz}$, 
$\mathrm{OH}), 4.77(1 \mathrm{H}, \mathrm{d}, J=4 \mathrm{~Hz}, \mathrm{OH}), 4.73-4.68\left(1 \mathrm{H}, \mathrm{m}, \mathrm{H} 2^{\prime}\right), 4.17-4.12\left(1 \mathrm{H}, \mathrm{m}, \mathrm{H1} 1^{\prime}\right), 3.82-3.79\left(1 \mathrm{H}, \mathrm{m}, \mathrm{H}^{\prime}\right)$, 3.69-3.66 (1H, m, H4'), 2.43-2.40 (1H, m, H5'a), 1.42-1.37 (1H, m, H5'b).

1-(2', $3^{\prime}, 4^{\prime}$-Trihydroxycyclopent-1'-yl)-6-decyl-3H-furano[2,3-d]-pyrimidine-2-one (5) was synthesized as described for compounds $3 \mathbf{a}-\mathbf{i}$, starting from $1-\left(2^{\prime}, 3^{\prime}, 4^{\prime}\right.$-trihydroxycyclopenten-1'-yl)-5-iodouracil 2. The product was purified using chloroform: methanol $(4: 1)$ as an eluent with $54 \%$ yield. $R_{f}$ 0.25 (system B). ${ }^{1} \mathrm{H}-\mathrm{NMR}\left(\mathrm{CD}_{3} \mathrm{OD}\right): 8.44(1 \mathrm{H}, \mathrm{s}, \mathrm{H} 4), 6.36(1 \mathrm{H}, \mathrm{s}, \mathrm{H} 5), 5.05-4.97\left(1 \mathrm{H}, \mathrm{m}, \mathrm{H} 2^{\prime}\right)$, 4.55-4.50 (1H, m, H1' $), 4.06-4.03\left(1 \mathrm{H}, \mathrm{m}, \mathrm{H} 3^{\prime}\right), 3.94-3.92\left(1 \mathrm{H}, \mathrm{m}, \mathrm{H} 4^{\prime}\right), 2.76-2.71\left(1 \mathrm{H}, \mathrm{m}, \mathrm{H} 5^{\prime} \mathrm{a}\right)$, 2.69-2.64 (2H, m, $\left.\mathrm{CH}_{2}\left(\mathrm{CH}_{2}\right)_{8} \mathrm{CH}_{3}\right), 1.73-1.66\left(3 \mathrm{H}, \mathrm{m}, \mathrm{H} 5^{\prime} \mathrm{b}+\mathrm{CH}_{2} \mathrm{CH}_{2}\left(\mathrm{CH}_{2}\right)_{7} \mathrm{CH}_{3}\right), 1.39-1.26(14 \mathrm{H}, \mathrm{m}$, $\left.\mathrm{CH}_{2} \mathrm{CH}_{2}\left(\mathrm{CH}_{2}\right)_{7} \mathrm{CH}_{3}\right), 0.68\left(3 \mathrm{H}, \mathrm{t}, J=8 \mathrm{~Hz}, \mathrm{CH}_{2}\left(\mathrm{CH}_{2}\right)_{8} \mathrm{CH}_{3}\right) .{ }^{13} \mathrm{C}-\mathrm{NMR}\left(\mathrm{CDCl}_{3}-\mathrm{CD}_{3} \mathrm{OD}\right): 171.35,160.15$, 156.56, 139.75, 108.87, 99.08, 76.68, 75.61, 73.77, 65.02, 35.54, 31.63, 29.25, 29.19, 29.00, 28.94, 28.66, 27.56, 26.57, 22.29, 13.01. HRMS: found $m / z$ 393.2384, calculated for $\mathrm{C}_{21} \mathrm{H}_{32} \mathrm{~N}_{2} \mathrm{O}_{5}[\mathrm{M}+\mathrm{H}]^{+} 393.2388$.

3.1.2. General Method for the Synthesis of

1-(4'-hydroxy-2'-cyclopenten-1'-yl)-6-alkyl-3H-pyrrolo[2,3-d]pyrimidine-2-ones and 1-(4'-hydroxy-2'-cyclopenten-1'-yl)-6-aryl-3H-pyrrolo[2,3-d]-pyrimidine-2-ones (4a-i).

To the corresponding 1-(4'-hydroxy-2'-cyclopenten-1'-yl)-6-alkyl-3H-furano[2,3-d]pyrimidine-2one or 1-(4'-hydroxy-2'-cyclopenten-1'-yl)-6-aryl-3H-furano[2,3-d]-pyrimidine-2-one (50 mg) a solution of $32 \% \mathrm{NH}_{3}$ in $\mathrm{MeOH}(15 \mathrm{~mL})$ was added. The reaction mixture was kept at $40{ }^{\circ} \mathrm{C}$ for $48 \mathrm{~h}$. Solvent then was evaporated in vacuo and a new portion of $32 \% \mathrm{NH}_{3}$ in $\mathrm{MeOH}$ was added $(15 \mathrm{~mL})$. The procedure was repeated three times controlling the progress of the reaction by TLC.

1-(4'-Hydroxy-2'-cyclopenten-1'-yl)-6-propyl-3H-pyrrolo[2,3-d]-pyrimidine-2-one (4a) was purified using PLC with chloroform: methanol (9:1) as an eluent with $70 \%$ yield. $\mathrm{R}_{f} 0.33$ (system A). ${ }^{1} \mathrm{H}-\mathrm{NMR}$ (DMSO- $\left.d_{6}\right): 11.05(1 \mathrm{H}, \mathrm{s}, \mathrm{NH}), 8.03(1 \mathrm{H}, \mathrm{s}, \mathrm{H} 4), 6.18-6.16\left(1 \mathrm{H}, \mathrm{m}, \mathrm{H} 2^{\prime}\right), 5.91(1 \mathrm{H}, \mathrm{s}, \mathrm{H} 5), 5.87-5.86(1 \mathrm{H}$, $\left.\mathrm{m}, \mathrm{H}^{\prime}\right), 5.69-5.66\left(1 \mathrm{H}, \mathrm{m}, \mathrm{H} 1^{\prime}\right), 5.21(1 \mathrm{H}, \mathrm{m}, \mathrm{OH}), 4.68\left(1 \mathrm{H}, \mathrm{m}, \mathrm{H}^{\prime}\right), 2.87-2.83\left(1 \mathrm{H}, \mathrm{m}, \mathrm{H} 5^{\prime} \mathrm{a}\right), 2.50(2 \mathrm{H}, \mathrm{t}$, $\left.J=8 \mathrm{~Hz}, \mathrm{CH}_{2} \mathrm{CH}_{2} \mathrm{CH}_{3}\right), 1.64-1.59\left(2 \mathrm{H}, \mathrm{m}, \mathrm{CH}_{2} \mathrm{CH}_{2} \mathrm{CH}_{3}\right), 1.38-1.34\left(1 \mathrm{H}, \mathrm{m}, \mathrm{H} 5^{\prime} \mathrm{b}\right), 0.89(3 \mathrm{H}, \mathrm{t}, J=8 \mathrm{~Hz}$, $\mathrm{CH}_{2} \mathrm{CH}_{2} \mathrm{CH}_{3}$ ). ${ }^{13} \mathrm{C}-\mathrm{NMR}$ (DMSO- $d_{6}$ ): $158.9,154.4,142.1,139.8,135.9,131.4,109.2,96.2,73.5,60.4,41.2$, 29.4, 20.9, 13.4. HRMS (ESI, $m / z$ ) of $\mathrm{C}_{14} \mathrm{H}_{17} \mathrm{~N}_{3} \mathrm{O}_{2}$ : calcd. for $[\mathrm{M}+\mathrm{Na}]^{+} 282.1213$, found 282.1211.

1-(4'-Hydroxy-2'-cyclopenten-1'-yl)-6-pentyl-3H-pyrrolo[2,3-d]-pyrimidine-2-one (4b). The product was purified using PLC with chloroform: methanol (9:1) as an eluent with $57 \%$ yield. $\mathrm{R}_{f} 0.33$ (system A). ${ }^{1} \mathrm{H}-\mathrm{NMR}\left(\mathrm{CD}_{3} \mathrm{OD}\right): 8.18(1 \mathrm{H}, \mathrm{s}, \mathrm{H} 4), 6.31-6.28\left(1 \mathrm{H}, \mathrm{m}, \mathrm{H} 2^{\prime}\right), 6.01(1 \mathrm{H}, \mathrm{m}, \mathrm{H} 5), 5.99-5.96(1 \mathrm{H}$, $\left.\mathrm{m}, \mathrm{H}^{\prime}\right), 5.85-5.81\left(1 \mathrm{H}, \mathrm{m}, \mathrm{H1} 1^{\prime}\right), 4.89\left(1 \mathrm{H}, \mathrm{m}, \mathrm{H} 4^{\prime}\right), 3.08-3.03\left(1 \mathrm{H}, \mathrm{m}, \mathrm{H}^{\prime} \mathrm{a}\right), 2.64(2 \mathrm{H}, \mathrm{t}, J=8 \mathrm{~Hz}$, $\left.\mathrm{CH}_{2} \mathrm{CH}_{2}\left(\mathrm{CH}_{2}\right)_{2} \mathrm{CH}_{3}\right), 1.75-1.68\left(2 \mathrm{H}, \mathrm{m}, \mathrm{CH}_{2} \mathrm{CH}_{2}\left(\mathrm{CH}_{2}\right)_{2} \mathrm{CH}_{3}\right), 1.57-1.49\left(1 \mathrm{H}, \mathrm{m}, \mathrm{H} 5^{\prime} \mathrm{b}\right), 1.40-1.35(4 \mathrm{H}$, $\left.\mathrm{m}, \mathrm{CH}_{2} \mathrm{CH}_{2}\left(\mathrm{CH}_{2}\right)_{2} \mathrm{CH}_{3}\right), 0.93\left(3 \mathrm{H}, \mathrm{t}, J=8 \mathrm{~Hz}, \mathrm{CH}_{2} \mathrm{CH}_{2}\left(\mathrm{CH}_{2}\right)_{2} \mathrm{CH}_{3}\right) .{ }^{13} \mathrm{C}-\mathrm{NMR}\left(\mathrm{CD}_{3} \mathrm{OD}\right): 158.6,156.3$, $143.8,139.5,136.0,131.3,111.2,96.4,74.2,61.7,41.2,31.1,27.6,27.5,22.0,12.9$. HRMS (ESI, $m / z)$ of $\mathrm{C}_{16} \mathrm{H}_{21} \mathrm{~N}_{3} \mathrm{O}_{2}$ : calcd. for $[\mathrm{M}+\mathrm{H}]^{+}$288.1706, found 288.1710.

1-(4'-Hydroxy-2'-cyclopenten-1'-yl)-6-hexyl-3H-pyrrolo[2,3-d]-pyrimidine-2-one (4c). The product was purified using PLC with chloroform: methanol (9:1) as an eluent with $64 \%$ yield. $R_{f} 0.33$ (system A). ${ }^{1} \mathrm{H}-\mathrm{NMR}\left(\mathrm{CD}_{3} \mathrm{OD}\right): 8.16(1 \mathrm{H}, \mathrm{s}, \mathrm{H} 4), 6.28-6.27\left(1 \mathrm{H}, \mathrm{m}, \mathrm{H2}{ }^{\prime}\right), 6.00(1 \mathrm{H}, \mathrm{m}, \mathrm{H} 5), 5.96-5.95(1 \mathrm{H}$, $\left.\mathrm{m}, \mathrm{H3}^{\prime}\right), 5.81\left(1 \mathrm{H}, \mathrm{m}, \mathrm{H} 1^{\prime}\right), 4.83-4.80\left(1 \mathrm{H}, \mathrm{m}, \mathrm{H} 4^{\prime}\right), 3.08-3.00\left(1 \mathrm{H}, \mathrm{m}, \mathrm{H} 5^{\prime} \mathrm{a}\right), 2.62(2 \mathrm{H}, \mathrm{t}, J=8 \mathrm{~Hz}$, $\left.\mathrm{CH}_{2} \mathrm{CH}_{2}\left(\mathrm{CH}_{2}\right)_{3} \mathrm{CH}_{3}\right), 1.70-1.66\left(2 \mathrm{H}, \mathrm{m}, \mathrm{CH}_{2} \mathrm{CH}_{2}\left(\mathrm{CH}_{2}\right)_{3} \mathrm{CH}_{3}\right), 1.54-1.48(1 \mathrm{H}, \mathrm{m}, \mathrm{H} 5$ 'b), 1.39-1.33 (6H, m, $\left.\mathrm{CH}_{2} \mathrm{CH}_{2}\left(\mathrm{CH}_{2}\right)_{3} \mathrm{CH}_{3}\right), 0.90\left(3 \mathrm{H}, \mathrm{t}, J=8 \mathrm{~Hz}, \mathrm{CH}_{2} \mathrm{CH}_{2}\left(\mathrm{CH}_{2}\right)_{3} \mathrm{CH}_{3}\right) .{ }^{13} \mathrm{C}-\mathrm{NMR}\left(\mathrm{CD}_{3} \mathrm{OD}\right):$ 160.0, 157.8, 145.2, 140.9, 137.4, 132.8, 112.6, 97.8, 75.6, 63.1, 42.6, 32.7, 29.9, 29.3, 29.0, 23.6, 14.3. HRMS (ESI, $m / z)$ of $\mathrm{C}_{17} \mathrm{H}_{23} \mathrm{~N}_{3} \mathrm{O}_{2}$ : calcd. for $[\mathrm{M}+\mathrm{H}]^{+}$302.1863, found 302.1868.

1-(4'-Hydroxy-2'-cyclopenten-1'-yl)-6-octyl-3H-pyrrolo[2,3-d]-pyrimidine-2-one (4d). The product was purified using PLC with chloroform: methanol (9:1) as an eluent with $89 \%$ yield. $\mathrm{R}_{f} 0.33$ (system A). ${ }^{1} \mathrm{H}-\mathrm{NMR}\left(\mathrm{CD}_{3} \mathrm{OD}\right): 8.18(1 \mathrm{H}, \mathrm{s}, \mathrm{H} 4), 6.31-6.29\left(1 \mathrm{H}, \mathrm{m}, \mathrm{H} 2^{\prime}\right), 6.02(1 \mathrm{H}, \mathrm{s}, \mathrm{H} 5), 5.98-5.96(1 \mathrm{H}$, $\left.\mathrm{m}, \mathrm{H}^{\prime}\right), 5.83\left(1 \mathrm{H}, \mathrm{m}, \mathrm{H} 1^{\prime}\right), 4.85-4.82\left(1 \mathrm{H}, \mathrm{m}, \mathrm{H} 4^{\prime}\right), 3.08-3.00\left(1 \mathrm{H}, \mathrm{m}, \mathrm{H} 5^{\prime} \mathrm{a}\right), 2.64(2 \mathrm{H}, \mathrm{t}, J=8 \mathrm{~Hz}$, $\left.\underline{\mathrm{CH}_{2}} \mathrm{CH}_{2}\left(\mathrm{CH}_{2}\right)_{5} \mathrm{CH}_{3}\right), 1.72-1.67\left(2 \mathrm{H}, \mathrm{m}, \mathrm{CH}_{2} \underline{\mathrm{CH}_{2}}\left(\mathrm{CH}_{2}\right)_{5} \mathrm{CH}_{3}\right), 1.56-1.48(1 \mathrm{H}, \mathrm{m}, \mathrm{H} 5$ 'b), 1.35-1.27 (10H, 
$\left.\mathrm{m}, \mathrm{CH}_{2} \mathrm{CH}_{2}\left(\mathrm{CH}_{2}\right)_{5} \mathrm{CH}_{3}\right), 0.91\left(3 \mathrm{H}, \mathrm{t}, J=8 \mathrm{~Hz}, \mathrm{CH}_{2} \mathrm{CH}_{2}\left(\mathrm{CH}_{2}\right)_{5} \mathrm{CH}_{3}\right) .{ }^{13} \mathrm{C}-\mathrm{NMR}$ (DMSO-d 6 ): 160.0, 157.8, 145.2, 140.9, 137.4, 132.8, 112.6, 97.9, 75.6, 63.1, 42.6, 33.0, 30.4, 30.3, 30.2, 29.3, 29.0, 23.7, 14.4. HRMS (ESI, $m / z$ ) of $\mathrm{C}_{19} \mathrm{H}_{27} \mathrm{~N}_{3} \mathrm{O}_{2}$ : calcd. for $[\mathrm{M}+\mathrm{Na}]^{+} 352.2176$, found 352.2177.

1-(4'-Hydroxy-2'-cyclopenten-1'-yl)-6-decyl-3H-pyrrolo[2,3-d]-pyrimidine-2-one (4e) was purified using PLC with chloroform: methanol (9:1) as an eluent with $67 \%$ yield. $\mathrm{R}_{f} 0.33$ (system $\left.\mathrm{A}\right) .{ }^{1} \mathrm{H}-\mathrm{NMR}\left(\mathrm{CD}_{3} \mathrm{OD}\right)$ : $8.18(1 \mathrm{H}, \mathrm{s}, \mathrm{H} 4), 6.31-6.28\left(1 \mathrm{H}, \mathrm{m}, \mathrm{H2}{ }^{\prime}\right), 6.02(1 \mathrm{H}, \mathrm{s}, \mathrm{H} 5), 5.99-5.96\left(1 \mathrm{H}, \mathrm{m}, \mathrm{H} 3^{\prime}\right), 5.85-5.81\left(1 \mathrm{H}, \mathrm{m}, \mathrm{H1}^{\prime}\right)$, 4.85-4.82 (1H, m, H4' $), 3.08-3.01\left(1 \mathrm{H}, \mathrm{m}, \mathrm{H} 5^{\prime} \mathrm{a}\right), 2.64\left(2 \mathrm{H}, \mathrm{t}, J=8 \mathrm{~Hz}, \mathrm{CH}_{2} \mathrm{CH}_{2}\left(\mathrm{CH}_{2}\right)_{7} \mathrm{CH}_{3}\right), 1.72-1.67$ (2H, m, $\left.\mathrm{CH}_{2} \mathrm{CH}_{2}\left(\mathrm{CH}_{2}\right)_{7} \mathrm{CH}_{3}\right), 1.57-1.49\left(1 \mathrm{H}, \mathrm{m}, \mathrm{H} 5{ }^{\prime} \mathrm{b}\right), 1.35-1.30\left(14 \overline{\mathrm{H}}, \mathrm{m}, \mathrm{CH}_{2} \mathrm{CH}_{2}\left(\mathrm{CH}_{2}\right)_{7} \mathrm{CH}_{3}\right), 0.91$ $\left(3 \mathrm{H}, \mathrm{t}, J=8 \mathrm{\textrm {Hz }}, \mathrm{CH}_{2} \mathrm{CH}_{2}\left(\mathrm{CH}_{2}\right)_{7} \mathrm{CH}_{3}\right) .{ }^{13} \mathrm{C}-\mathrm{NMR}$ (DMSO-d $\left.{ }_{6}\right): 160.0,157.7,145.2,140.9,137.4,132.8$, 112.6, 97.9, 75.6, 63.1, 42.6, 33.0, 30.6, 30.6, $30.4 \times 2,30.2,29.3,29.0,23.7,14.4$. HRMS (ESI, $m / z)$ of $\mathrm{C}_{21} \mathrm{H}_{31} \mathrm{~N}_{3} \mathrm{O}_{2}$ : calcd. for $[\mathrm{M}+\mathrm{Na}]^{+} 380.2308$, found 380.2309 .

1-(4'-Hydroxy-2'-cyclopenten-1'-yl)-6-dodecyl-3H-pyrrolo[2,3-d]-pyrimidine-2-one (4f) was purified using PLC with chloroform: methanol (9:1) as an eluent with $66 \%$ yield. $\mathrm{R}_{f} 0.38$ (system A). ${ }^{1} \mathrm{H}-\mathrm{NMR}\left(\mathrm{CDCl}_{3}\right)$ : $8.28(1 \mathrm{H}, \mathrm{s}, \mathrm{H} 4), 6.37-6.35\left(1 \mathrm{H}, \mathrm{m}, \mathrm{H} 2^{\prime}\right), 5.92(1 \mathrm{H}, \mathrm{s}, \mathrm{H} 5), 5.88-5.87\left(1 \mathrm{H}, \mathrm{m}, \mathrm{H} 3^{\prime}\right), 5.80-5.77\left(1 \mathrm{H}, \mathrm{m}, \mathrm{H} 1^{\prime}\right)$, 4.95-4.92 (1H, m, H4' $), 3.04-2.094\left(1 \mathrm{H}, \mathrm{m}, \mathrm{H}^{\prime} \mathrm{a}\right), 2.70\left(2 \mathrm{H}, \mathrm{t}, J=8 \mathrm{~Hz}, \mathrm{CH}_{2} \mathrm{CH}_{2}\left(\mathrm{CH}_{2}\right)_{9} \mathrm{CH}_{3}\right), 1.82-1.77$ $\left(2 \mathrm{H}, \mathrm{m}, \mathrm{CH}_{2} \mathrm{CH}_{2}\left(\mathrm{CH}_{2}\right)_{9} \mathrm{CH}_{3}\right), 1.71-1.66\left(1 \mathrm{H}, \mathrm{m}, \mathrm{H} 5{ }^{\prime} \mathrm{b}\right), 1.36-1.26\left(18 \mathrm{H}, \mathrm{m}, \mathrm{CH}_{2} \mathrm{CH}_{2}\left(\mathrm{CH}_{2}\right)_{9} \mathrm{CH}_{3}\right), 0.89$ $\left(3 \mathrm{H}, \mathrm{t}, J=8 \mathrm{\textrm {Hz }}, \mathrm{CH}_{2} \mathrm{CH}_{2}\left(\mathrm{CH}_{2}\right)_{9} \mathrm{CH}_{3}\right) .{ }^{13} \mathrm{C}-\mathrm{NMR}\left(\mathrm{CDCl}_{3}\right): 156.9,153.8,144.6,140.4,138.2,131.6,111.2$, $96.9,74.9,62.5,41.3,32.0,29.7 \times 4,29.5,29.4,29.3,28.1 \times 2,22.7,14.2$. HRMS (ESI, $m / z$ ) of $\mathrm{C}_{23} \mathrm{H}_{35} \mathrm{~N}_{3} \mathrm{O}_{2}$ : calcd. for $[\mathrm{M}+\mathrm{H}]^{+} 386.2802$, found 386.2804 .

1-(4'-Hydroxy-2'-cyclopenten-1'-yl)-6-phenyl-3H-pyrrolo[2,3-d]-pyrimidine-2-one (4g) was purified using PLC with chloroform: methanol (9:1) as an eluent with $71 \%$ yield. $\mathrm{R}_{f} 0.33$ (system A). ${ }^{1} \mathrm{H}-\mathrm{NMR}$ (CD $\left.{ }_{3} \mathrm{OD}\right): 8.33(1 \mathrm{H}, \mathrm{s}, \mathrm{H} 4), 7.75-7.73(2 \mathrm{H}, \mathrm{m}, \mathrm{Ph}), 7.45-7.42(2 \mathrm{H}, \mathrm{m}, \mathrm{Ph}), 7.38-7.36(1 \mathrm{H}, \mathrm{m}, \mathrm{Ph}), 6.66$ $(1 \mathrm{H}, \mathrm{s}, \mathrm{H} 5), 6.32-6.30\left(1 \mathrm{H}, \mathrm{m}, \mathrm{H} 2^{\prime}\right), 6.00-5.98\left(1 \mathrm{H}, \mathrm{m}, \mathrm{H} 3^{\prime}\right), 5.82\left(1 \mathrm{H}, \mathrm{m}, \mathrm{H} 1^{\prime}\right), 4.86-4.82\left(1 \mathrm{H}, \mathrm{m}, \mathrm{H} 4^{\prime}\right)$, 3.10-3.02 (1H, m, H5'a), 1.59-1.53 (1H, m, H5'b). ${ }^{13} \mathrm{C}_{-\mathrm{NMR}}\left(\mathrm{CD}_{3} \mathrm{OD}\right): 160.7,157.8,142.4,141.1,139.1$, 132.6, 132.0, $130.1 \times 2,129.8,126.4 \times 2,112.8,97.9,75.6,63.4,42.7$. HRMS (ESI, $m / z$ ) of $\mathrm{C}_{17} \mathrm{H}_{15} \mathrm{~N}_{3} \mathrm{O}_{2}$ : calcd. for $[\mathrm{M}+\mathrm{H}]^{+} 294.1237$, found 294.1233.

1-(4'-Hydroxy-2'-cyclopenten-1'-yl)-6-(4-tertbutylphenyl)-3H-pyrrolo[2,3-d]-pyrimidine-2-one (4h) was purified using PLC with chloroform: methanol (9:1) as an eluent with $61 \%$ yield. $\mathrm{R}_{f} 0.40$ (system A). ${ }^{1} \mathrm{H}-\mathrm{NMR}\left(\mathrm{CDCl}_{3}\right): 8.12(1 \mathrm{H}, \mathrm{s}, \mathrm{H} 4), 7.58(2 \mathrm{H}, \mathrm{d}, J=8 \mathrm{~Hz}, \mathrm{Ph}), 7.43(2 \mathrm{H}, \mathrm{d}, J=8 \mathrm{~Hz}, \mathrm{Ph}), 6.39(1 \mathrm{H}, \mathrm{s}, \mathrm{H} 5)$, 6.29-6.27 (1H, m, H2' $), 5.88-5.86\left(1 \mathrm{H}, \mathrm{m}, \mathrm{H} 3^{\prime}\right), 5.82\left(1 \mathrm{H}, \mathrm{m}, \mathrm{H} 1^{\prime}\right), 4.87\left(1 \mathrm{H}, \mathrm{m}, \mathrm{H} 4^{\prime}\right), 3.06-3.00(1 \mathrm{H}, \mathrm{m}$, $\left.\mathrm{H}^{\prime} \mathrm{a}\right), 1.66-1.62\left(1 \mathrm{H}, \mathrm{m}, \mathrm{H} 5^{\prime} \mathrm{b}\right), 1.32(9 \mathrm{H}, \mathrm{s}, \mathrm{tBu}) .{ }^{13} \mathrm{C}-\mathrm{NMR}\left(\mathrm{CDCl}_{3}\right): 159.0,155.8,152.2,140.9,139.7$, 137.2, 131.9, 127.5, $126.0 \times 2,124.9 \times 2,111.5,95.6,74.6,62.3,41.3,34.7,31.1 \times 3$. HRMS $(E S I, m / z)$ of $\mathrm{C}_{21} \mathrm{H}_{23} \mathrm{~N}_{3} \mathrm{O}_{2}$ : calcd. for $[\mathrm{M}+\mathrm{H}]^{+} 350.1863$, found 350.1864 .

1-(4'-Hydroxy-2'-cyclopenten-1'-yl)-6-(4-pentylphenyl)-3H-pyrrolo[2,3-d]-pyrimidine-2-one (4i). The product was purified using two-step chromatography. The first column was eluted with chloroform: methanol (98:2 to 97:3) and the second one with hexane: ethyl acetate (1:4) to ethyl acetate: methanol (97:3) as an eluent to give (4i) with $72 \%$ yield. $\mathrm{R}_{f} 0.36$ (system A). ${ }^{1} \mathrm{H}-\mathrm{NMR}\left(\mathrm{CDCl}_{3}-\mathrm{CD}_{3} \mathrm{OD}\right): 8.27(1 \mathrm{H}$, s, $\mathrm{H} 4), 7.62(2 \mathrm{H}, \mathrm{d}, J=8.5 \mathrm{~Hz}, \mathrm{Ph}), 7.23(2 \mathrm{H}, \mathrm{d}, J=8.5 \mathrm{~Hz}, \mathrm{Ph}), 6.58(1 \mathrm{H}, \mathrm{s}, \mathrm{H} 5), 6.29-6.27\left(1 \mathrm{H}, \mathrm{m}, \mathrm{H2} 2^{\prime}\right)$, 5.97-5.95 (1H, m, H3' $), 5.81-5.79\left(1 \mathrm{H}, \mathrm{m}, \mathrm{H}^{\prime}\right), 4.83-4.80\left(1 \mathrm{H}, \mathrm{m}, \mathrm{H} 4^{\prime}\right), 3.09-2.97\left(1 \mathrm{H}, \mathrm{m}, \mathrm{H} 5^{\prime} \mathrm{a}\right), 2.62(2 \mathrm{H}$, $\left.\mathrm{t}, J=9 \mathrm{~Hz}, \mathrm{CH}_{2} \mathrm{CH}_{2}\left(\mathrm{CH}_{2}\right)_{2} \mathrm{CH}_{3}\right), 1.64-1.55\left(3 \mathrm{H}, \mathrm{m}, \mathrm{H} 5^{\prime} \mathrm{b}\right.$ and $\left.\mathrm{CH}_{2} \mathrm{CH}_{2}\left(\mathrm{CH}_{2}\right)_{2} \mathrm{CH}_{3}\right), 1.34-1.29(4 \mathrm{H}, \mathrm{m}$, $\left.\mathrm{CH}_{2} \mathrm{CH}_{2}\left(\mathrm{CH}_{2}\right)_{2} \mathrm{CH}_{3}\right), 0.88\left(3 \mathrm{H}, \mathrm{t}, \mathrm{J}=9 \mathrm{~Hz}, \mathrm{CH}_{2} \mathrm{CH}_{2}\left(\mathrm{CH}_{2}\right)_{2} \mathrm{CH}_{3}\right) .{ }^{13} \mathrm{C}-\mathrm{NMR}\left(\mathrm{CDCl}_{3}-\mathrm{CD}_{3} \mathrm{OD}\right): 159.2$, 156.4, 143.8, 141.2, 139.67, 137.2, 131.3, $128.7 \times 2,125.7,125.0 \times 2,111.6,95.8,78.0,74.2,61.9,41.3,35.2$, $31.2,30.8,22.2,13.0$. HRMS (ESI, $m / z$ ) of $\mathrm{C}_{22} \mathrm{H}_{25} \mathrm{~N}_{3} \mathrm{O}_{2}$ : calcd. for $[\mathrm{M}+\mathrm{H}]^{+} 364.2020$, found 364.2020. 


\subsection{Biological Assay}

\subsubsection{Cell Cultures}

Human KB-3-1 epidermoid carcinoma cell line, human HeLa cervical epithelioid carcinoma cell line, human HuTu-80 duodenal cancer cells, human A549 lung carcinoma epithelial cells, mouse B16 melanoma cell line and human hFF3 fibroblast cells were obtained from the Russian Cell Culture Collection (St. Petersburg, Russia) and were cultured in DMEM (hFF3 cells in IMDM) supplemented with $10 \%(v / v)$ heat-inactivated fetal bovine serum, penicillin $\left(100 \mathrm{U} \mathrm{mL}^{-1}\right)$, streptomycin $(100 \mu \mathrm{g}$ $\left.\mathrm{mL}^{-1}\right)$ and amphotericin $\left(250 \mu \mathrm{g} \mathrm{mL}^{-1}\right)$. Cells were maintained in a humidified atmosphere of $5 \%$ $\mathrm{CO}_{2}$ at $37^{\circ} \mathrm{C}$.

All compounds were dissolved in dimethylsulfoxide (DMSO) and stock solutions (10 mmol L ${ }^{-1}$ ) were stored at $-20^{\circ} \mathrm{C}$.

After treatments, both floating and adherent scrapped cells were collected by centrifugation and used for further analysis.

\subsubsection{Cell Viability Analysis by MTT Assay}

Cells growing in the logarithmic phase were seeded in triplicate in 96-well plates at a density of $5 \times 10^{3}$ cells per well for HeLa and HuTu- 80 cells, $7 \times 10^{3}$ cells per well for KB-3-1 and hFF3, $10 \times 10^{3}$ for $\mathrm{A} 549$ and $20 \times 10^{3}$ for B16. The plates were incubated at $37{ }^{\circ} \mathrm{C}$ in a humidified $5 \% \mathrm{CO}_{2}$ atmosphere. Cells were allowed to adhere to the surface for $24 \mathrm{~h}$ and then tested compounds were added at different concentrations and incubation was continued for $48 \mathrm{~h}$. Then [3-(4,5-dimethylthiazol-2-yl)-2,5-diphenyltetrazolium bromide] (MTT) solution (10 $\mu \mathrm{L}, 5 \mathrm{mg} \mathrm{mL}^{-1}$ ) was added to each well and the incubation was continued for an additional $3 \mathrm{~h}$. The dark blue formazan crystals formed within the healthy cells were solubilized with DMSO and the absorbance was measured using a Multiscan RC plate reader at $570 \mathrm{~nm}$. The $\mathrm{IC}_{50}$ was determined as the compound concentration required to decrease the $A_{570}$ to $50 \%$ compared to the control (no tested compounds, DMSO) and was determined by interpolation from dose-response curves.

\subsubsection{Apoptosis Detection by Annexin V Staining}

Exponentially growing KB-3-1 cells in 6-well plates $\left(5 \times 10^{5}\right.$ cells per well) were treated with $3 \mathbf{i}(5,10$ and $20 \mu \mathrm{M})$ or with $0.1 \%(v / v)$ DMSO as a control for $48 \mathrm{~h}$. The cells were stained with Annexin V-FITC and propidium iodide by the Annexin-FITC apoptosis staining/detection kit (Abcam) according to the instruction of the manufacturer. Briefly, cells were collected by scrapping, washed twice with cold PBS, and centrifuged (400 g, $5 \mathrm{~min})$. Cells were resuspended in binding buffer $(500 \mu \mathrm{L})$ and Annexin V-FITC $(5 \mu \mathrm{L})$ and PI $(5 \mu \mathrm{L})$ were added. Cells were incubated for $5 \mathrm{~min}$ at $20{ }^{\circ} \mathrm{C}$ in the dark. Finally, binding buffer $(300 \mu \mathrm{L})$ was added to each tube, and the amount of apoptotic cells in samples were analyzed by flow cytometry. For each sample, 10,000 ungated events were acquired. Annexin V + PI - cells represent the early apoptotic populations. Annexin V + PI + cells represent either late apoptotic or secondary necrotic populations.

\subsubsection{Mitochondria Depolarization Analysis}

Mitochondria involvement in apoptosis was measured by mitochondrial depolarization occurring early during onset of apoptosis. KB-3-1 cells were incubated with $3 \mathbf{i}(5,10$ and $20 \mu \mathrm{M})$ or $0.1 \%(v / v)$ DMSO as a control for $48 \mathrm{~h}$. Then, cells were collected and incubated in complete media in the dark with mitochondrial potential sensor JC-1 $\left(5 \mu \mathrm{g} \mathrm{mL}{ }^{-1}\right)$ at $37{ }^{\circ} \mathrm{C}$ for $30 \mathrm{~min}$, washed with cold PBS and resuspended in PBS $(400 \mu \mathrm{L})$. Fluorescences of J-aggregate and J-monomer were recorded in the fluorescence channels 2 (FL2) and 1 (FL1), respectively, with flow cytometer «FC500». Necrotic fragments were electronically gated out, on the basis of morphological characteristics on the forward light scatter versus side light scatter dot plot. 


\title{
4. Conclusions
}

The comparative evaluation of the effects of synthesized nucleoside analogues on the growth and viability of tumor cell cultures from various origins and on normal cells has revealed that cytotoxicity depends on both the type of bicyclic system (pyrrolo- or furano[2,3-d]pyrimidine) and the structure of a substituent in the 6th position of the heterocyclic base. Furano[2,3-d]pyrimidine 3i, bearing pentylphenyl substituent, is the most promising among synthesized $5^{\prime}$-norcarbocyclic derivatives of 6-substituted bicyclic pyrrolo- and furano[2,3-d]pyrimidines. This demonstrated inhibitory activities with respect to tumor cells with the selectivity index value about 15-20 depending on the nature and origin of tumor cells. In an attempt to understand the mechanism of the action, we showed that $3 \mathbf{i}$ induces cell death by apoptosis pathway with the dissipation of mitochondrial potential.

Supplementary Materials: Copies of the NMR spectra are available online.

Author Contributions: A.A.K., E.S.M. and A.L.K. conceived, designed and performed the chemical synthesis; E.B.L. and M.A.Z. designed and performed cell assays and evaluated biological properties of the compounds; P.N.S. performed HRMS analysis and analyzed the relevant data. A.A.K., E.S.M., E.B.L., M.A.Z., P.N.S., S.N.K. and A.L.K. analyzed the data; S.N.K. contributed reagents/materials/analysis tools; A.A.K., E.S.M., E.B.L., P.N.S. and A.L.K. wrote the paper.

Funding: This research was supported by the Russian Foundation for Basic Research (RFBR, grant No. 16-04-01022) and by the Program of fundamental research for state academies for 2013-2020 years (No. 01201363818).

Conflicts of Interest: The authors declare no conflict of interest.

\section{Abbreviations}

\author{
MTT 3-(4,5-Dimethylthiazol-2-yl)-2,5-diphenyltetrazolium bromide \\ NMMO N-methylmorpholine $N$-oxide \\ JC-1 5, 5 5 , 6, $6^{\prime}$-tetrachloro-1,1' $1^{\prime}, 3,3^{\prime}$-tetraethylbenzimidazolylcarbocyanine iodide \\ PI propidium iodide \\ PLC preparative layer chromatography \\ IC50 the compound concentration that results in 50\% cell survival as measured by the MTT assay
}

\section{References}

1. Jordheim, L.P.; Durantel, D.; Zoulim, F.; Dumontet, C. Advances in the development of nucleoside and nucleotide analogues for cancer and viraldiseases. Nat. Rev. Drug Discov. 2013, 12, 447-464. [CrossRef] [PubMed]

2. Galmarini, C.; Popowycz, F.; Joseph, B. Cytotoxic Nucleoside Analogues: Different Strategies to Improve their Clinical Efficacy. Curr. Med. Chem. 2008, 15, 1072-1082. [CrossRef] [PubMed]

3. McGuigan, C.; Yarnold, C.J.; Jones, G.; Velázquez, S.; Barucki, H.; Brancale, A.; Andrei, G.; Snoeck, R.; De Clercq, E.; Balzarini, J. Potent and selective inhibition of varicella-zoster virus (VZV) by nucleoside analogues with an unusual bicyclic base. J. Med. Chem. 1999, 42, 4479-4484. [CrossRef] [PubMed]

4. Balzarini, J.; McGuigan, C. Bicyclic pyrimidine nucleoside analogues (BCNAs) as highly selective and potent inhibitors of varicella-zoster virus replication. J. Antimicrob. Chemother. 2002, 50, 5-9. [CrossRef] [PubMed]

5. Jahnz-Wechmann, Z.; Framski, G.; Januszczyk, P.; Boryski, J. Bioactive fused heterocycles: Nucleoside analogues with an additional ring. Eur. J. Med. Chem. 2015, 97, 388-396. [CrossRef] [PubMed]

6. Migliore, M.D.; Zonta, N.; McGuigan, C.; Henson, G.; Andrei, G.; Snoeck, R.; Balzarini, J. Synthesis and Antiviral Activity of the Carbocyclic Analogue of the Highly Potent and Selective Anti-VZV Bicyclo Furano Pyrimidines. J. Med. Chem. 2007, 50, 6485-6492. [CrossRef] [PubMed]

7. Dincer, S.; Cetin, K.T.; Onay-Besikci, A.; Olgen, S. Synthesis, biological evaluation and docking studies of new pyrrolo[2,3-d] pyrimidine derivatives as Src family-selective tyrosine kinase inhibitors. J. Enzyme Inhib. Med. Chem. 2013, 28, 1080-1087. [CrossRef] [PubMed]

8. Aziz, M.A.; Serya, R.A.T.; Lasheen, D.S.; Abouzid, K.A.M. Furo[2,3-d]pyrimidine based derivatives as kinase inhibitors and anticancer agents. Future J. Pharm. Sci. 2016, 2, 1-8. [CrossRef] 
9. Romeo, R.; Giofre, S.V.; Garozzo, A.; Bisignano, B.; Corsaro, A.; Chiacchio, M.A. Synthesis and biological evaluation of furopyrimidine N,O-nucleosides. Bioorg. Med. Chem. 2013, 21, 5688-5693. [CrossRef] [PubMed]

10. Framski, G.; Wawrzyniak, D.; Jahnz-Wechmann, Z.; Szymanska-Michalak, A.; Barciszewski, J.; Boryski, J.; Kraszewski, A.; Stawinski, J. New Applications of 6-Alkyl-2,3dihydrofurano[2,3-d]pyrimidin-2(1H)-one and 6-Alkyl-2,3-dihydropyrrolo[2,3-d]pyrimidin-2(3H,7H)-one Nucleosides: Anticancer Properties. In Proceedings of the XXI Round Table on Nucleosides, Nucleotides and Nucleic Acids "Chemical Biology of Nucleic Acids", Poznań, Poland, 24-28 August 2014; Electronic Abstract Book, Poster 13. IS3NA, 2014.

11. Framski, G.; Wawrzyniak, D.; Jahnz-Wechmann, Z.; Szymanska-Michalak, A.; Kraszewski, A.; Barciszewski, J.; Boryski, J.; Stawinski, J. Searching for anti-glioma activity. Ribonucleoside analogues with modifications in nucleobase and sugar moieties. Acta Biochim. Pol. 2016, 63, 765-771. [CrossRef] [PubMed]

12. Matyugina, E.; Logashenko, E.; Zenkova, M.; Kochetkov, S.; Khandazhinskaya, A. 5'-Norcarbocyclic analogues of furano[2,3-d] pyrimidine nucleosides. Heterocycl. Commun. 2015, 21, 259-262. [CrossRef]

13. Matyugina, E.S.; Khandazhinskaya, A.L.; Chernousova, L.N.; Andreevskaya, S.N.; Smirnova, T.G.; Chizhov, A.O.; Karpenko, I.L.; Kochetkov, S.N.; Alexandrova, L.A. The Synthesis and Antituberculosis Activity of 5'-Nor Carbocyclic Uracil Derivatives. Bioorg. Med. Chem. 2012, 20, 6680-6686. [CrossRef] [PubMed]

14. Khandazhinskaya, A.L.; Shirokova, E.A.; Shipitsin, A.V.; Karpenko, I.L.; Belanov, E.F.; Kukhanova, M.K.; Yasko, M.V. Adenosine N1-oxide analogues as inhibitors of orthopox virus replication. Collect. Czech. Chem. Commun. 2006, 71, 1107-1121. [CrossRef]

15. Matyugina, E.S.; Khandazhinskaya, A.L.; Kochetkov, S.N. Carbocyclic nucleoside analogues: Classification, target enzymes, mechanisms of action and synthesis. Russ. Chem. Rev. 2012, 81, 729-746. [CrossRef]

16. Ainai, T.; Wang, Y.-G.; Tokoro, Y.; Kobayashi, Y. Highly Stereoselective Synthesis of Aristeromycin through Dihydroxylation of 4-Aryl-1-azido-2-cyclopentenes. J. Org. Chem. 2004, 69, 655-659. [CrossRef] [PubMed]

17. Fuertes, M.A.; Castilla, J.; Alonso, C.; Pérez, J.M. Novel concepts in the development of platinum antitumor drugs. Curr. Med. Chem. Anticancer Agents 2002, 2, 539-551. [CrossRef] [PubMed]

Sample Availability: Samples of the compounds are not available from the authors.

(C) 2018 by the authors. Licensee MDPI, Basel, Switzerland. This article is an open access article distributed under the terms and conditions of the Creative Commons Attribution (CC BY) license (http://creativecommons.org/licenses/by/4.0/). 